British white population, but there is evidence that such standards are applicable for measuring child growth in other cultures, ${ }^{17}$ although this is controversial. ${ }^{18}$ As ours was a retrospective study data were not available on the children's iron and calcium metabolism; and we did not have details about the economic circumstances of the Asian and control families and their social class distribution.

Language problems may also have contributed to the poorer result in the Asian children, since the treatment and its complications were difficult to explain to people whose first language was not English and who were not accustomed to Western medicines. This factor may also have contributed to the higher incidence of deaths in remission among the Asian children as their parents may have been insufficiently aware of early signs and symptoms of infection and of other complications of chemotherapy. Poor communication might also have led to poor compliance, although there was no increased rate of leukaemic relapse in the Asians compared with the white controls.

Improvement in the results of treating Asian children with acute lymphoblastic leukaemia might be achieved by better attention to nutrition and by further attempts to overcome communication difficulties. More studies are required to determine whether other factors may influence the outcome in Asian children.

We thank Dr H E M Kay, Miss M Gilham, Miss A M Fenwick, and Dr A Rankin for help; Dr J Peto for permission to quote his analysis of the prognostic features in the UKALL II to V trials; the Leukaemia Research Fund for financial support; and Mrs K Evans and Mrs $\mathbf{N}$ Hartley for typing the manuscript.

\section{References}

1 George SL, Fernbach DJ, Vietti TJ, et al. Factors influencing survival in pediatric acute leukemia. The SWCCSG experience 1958-1970. Cancer $1973 ; 32: 1542-53$.
2 Walters TR, Bushore M, Simone J. Poor prognosis in Negro children with acute lymphoblastic leukaemia. Cancer 1972;29:210-4.

3 Pendergrass TW, Hoover R, Godwin JD. Prognosis of black children with acute lymphoblastic leukaemia. Med Pediatr Oncol 1975;1:143-8.

4 Szklo M, Gordis L, Tonascia J, Kaplan E. The changing survivorship of white and black children with leukaemia. Cancer 1978;42:59-66.

5 Peto R, Pike MC, Armitage P, et al. Design and analysis of randomised clinical trials requiring prolonged observation of each patient. II. Analysis and examples. Br $\mathcal{F}$ Cancer 1977;35:1-39.

6 Tanner JM, Whitehouse RH, Takaishi $M$. Standards from birth to maturity for height, weight, height velocity and weight velocity: British children, 1965. Part I. Arch Dis Child 1966;41:454-71.

${ }^{7}$ Tanner JM, Whitehouse RH, Takaishi $M$. Standards from birth to maturity for height, weight, height velocity and weight velocity: British children, 1965. Part II. Arch Dis Child 1966;41:613-35.

${ }^{8}$ Chessells JM, Hardisty RM, Rapson NT, Greaves MF. Acute lymphoblastic leukaemia in children. Classification and prognosis. Lancet 1977; ii:1307-9.

${ }^{9}$ Robison L, Sather H, Coccia PF, et al. Assessment of the inter-relationship of prognostic factors in childhood acute lymphoblastic leukaemia. $A m \mathcal{F}$ Pediatr Hematol Oncol 1980;2:5-12.

10 Gordis L, Moyses S, Thompson B, Kaplan A, Tonascia JA. An apparent increase in the incidence of acute non-lymphocytic leukaemia in black children. Cancer $1981 ; 47: 2763-8$.

11 Anonymous. Leukaemia in black and white. (Editorial.) Lancet 1981 ;ii: 732-3.

12 Adelstein AM, Davies IM, Weatherall JA. Perinatal and infant mortality: social and biological factors 1975-77. London: HMSO, 1980. (Studies in Medical and Population Subjects No 41.)

13 Preece MA, Ford JA, McIntosh WB, Dunnigan MG, Tomlinson S, O'Riordan JLH. Vitamin D deficiency among Asian immigrants to Britain. Lancet 1973;i:907-10.

14 Cooke WT, Swan CHJ, Asquith P, Melikian V, McFeely WE. Serum alkaline phosphatase and rickets in urban schoolchildren. $\mathrm{Br} \mathrm{Med} \mathcal{F}$ $1973 ; \mathrm{i}: 324-7$.

15 Stuart J, Schwartz FCM, Little AJ, Raine DN. Screening for abnormal haemoglobins: a pilot study. $B r$ Med f 1973;iv:284-7.

${ }^{16}$ van Eys J. Nutritional therapy in children with cancer. Cancer Res 1977; 37:2457-61.

17 Graiter PL, Gentry EM. Measuring children: one reference for all. Lancet 1981 ;ii :297-9.

18 Euebio JS, Nubé M. Attainable growth. Lancet 1981 ;ii:1223.

(Accepted 19 fanuary 1983)

\title{
Incidence of self poisoning in patients prescribed psychotropic drugs
}

\author{
KEREN SKEGG，D C G SKEGG，S M RICHARDS
}

\begin{abstract}
The drugs most commonly used in self poisoning are the psychotropics, but the proportion of patients given these drugs who take overdoses is unknown. In a prospective study of 43117 people in Oxfordshire, prescriptions issued by general practitioners were linked with records of hospital admissions and deaths. During two years there were 79 episodes of deliberate self poisoning leading to hospital admission or death. The number of patients who took overdoses of psychotropic drugs was small in relation to the total number pre-
\end{abstract}

University of Otago Medical School, Dunedin, New Zealand KEREN SKEGG, MB, MRCPSYCH, senior lecturer in psychological medicine D C G SKEGG, MB, DPHIL, professor of preventive and social medicine

Radcliffe Infirmary, Oxford OX2 6HE

S M RICHARDS, BA, DPHIL, research assistant

Correspondence and requests for reprints to: Dr Keren Skegg. scribed such drugs. Of 5600 people aged 10 or older who received psychotropic drugs during one year, 17 (3.0 per 1000) poisoned themselves with these drugs within 12 months. The rate of self poisoning with psychotropic drugs declined significantly with increasing age $(p<$ 0.001).

Almost three quarters of the patients who took overdoses of prescribed psychotropics received further psychotropic drugs during the three months after their admission to hospital.

\section{Introduction}

Whenever a medicine is prescribed there is a risk that the patient may deliberately take an overdose. Despite extensive research on self poisoning, ${ }^{12}$ the proportion of patients given drugs who poison themselves is not known. Such information is especially important for evaluating the clinical use of psychotropic drugs. ${ }^{34} \mathrm{We}$ were able to examine this question during a prospective study of medicines prescribed in general practice. 


\section{Methods}

The overall design and conduct of the study have been described elsewhere. ${ }^{5}$ For two years the following records were linked for all patients registered with 16 general practitioners in the Oxford region: (a) details of basic attributes, such as sex and age; $(b)$ prescriptions issued by general practitioners and dispensed; and (c) records of hospital admissions, obstetric deliveries, and deaths. A total of 43117 people were included during the two years, but this analysis is confined to the 34870 people aged 10 years or older.

A computer listing was produced of all the records of patients who were admitted to hospital or died (in or out of hospital) with a diagnosis of "Adverse effect of medicinal agents" (International Classification of Diseases, 8th revision, rubrics N960-N979). We examined these patients' hospital case notes or, if these were unavailable, their general practice case notes. Episodes were considered to be cases of self poisoning if they entailed "deliberate acute self administration of a drug with the intention of causing or risking death or harm, or in order to give the impression of such intention." 6 The drugs taken by each patient were compared with those that he or she had been prescribed. In addition to studying rates of self poisoning with prescribed drugs, we examined the prescriptions written by general practitioners after an episode of self poisoning.

\section{Results}

A total of 79 episodes of self poisoning leading to hospital admission or (in one case) death occurred in 76 patients. Table I shows the age distribution of these patients.

$\begin{aligned} & \text { TABLE I-No of patients poisoning themselves with } \\
& \text { prescribed or non-prescribed drugs, by sex and age }\end{aligned}$
\begin{tabular}{ccc} 
Age (years) & No of males & No of females \\
\hline $10-14$ & 1 & 5 \\
$15-29$ & 14 & 24 \\
$30-44$ & 3 & 18 \\
$45-59$ & 1 & 7 \\
$\geqslant 60$ & 2 & 1 \\
\hline Total & 21 & 55
\end{tabular}

Patients took an overdose of one medicine in 56 episodes, two medicines in 14 episodes, and three or more medicines in nine episodes. A psychotropic drug was taken in a total of 53 episodes $(67 \%)$ and an analgesic in $31(39 \%)$. The medicines used most commonly were diazepam (22 episodes), aspirin (17), and nitrazepam (11).

\section{SELF POISONING WITH PRESCRIBED DRUGS}

In 38 episodes, affecting 36 patients, at least one of the drugs taken had been prescribed by the general practitioner during the study period, as indicated by our records of prescriptions dispensed. The drugs concerned all fell into four classes: psychotropics (32 episodes), analgesics (3), anticonvulsants (3), and anticoagulants (1). Drugs taken had been prescribed in the week before admission in 13 cases and in the month before in 27 cases. The period between prescription of the drug and self poisoning ranged from less than a day to 157 days (median 13 days).

In 15 of the 38 episodes the patient had also been prescribed-on the same day or subsequently-other drugs that were not used in the self poisoning. These unused medicines included psychotropic drugs in six cases. On the other hand, in eight of the 38 episodes the patient took drugs in addition to those known to have been prescribed by the general practitioner. The drugs concerned were analgesics in six cases and barbiturates in the other two cases.

The 31 patients who poisoned themselves with psychotropic drugs represented only $0.38 \%$ of the 8235 people aged 10 or older who were given these drugs during the two years. Table II shows the number of patients who took overdoses of different groups of psychotropic drugs in relation to the total number who received prescriptions during the two years. Antidepressants were associated with the highest rate of self poisoning, though the difference between
TABLE II-No of patients poisoning themselves with prescribed psychotropic $\mathrm{W}$ drugs in relation to total numbers receiving such drugs in a two year period

\begin{tabular}{|c|c|c|c|c|c|c|c|c|c|}
\hline & \multicolumn{3}{|c|}{$\begin{array}{l}\text { No who received } \\
\text { prescriptions }\end{array}$} & \multicolumn{3}{|c|}{$\begin{array}{l}\text { No taking } \\
\text { overdose }\end{array}$} & \multicolumn{3}{|c|}{$\begin{array}{l}\text { Rate } / 1000 \\
\text { recipients }\end{array}$} \\
\hline & M & $\mathrm{F}$ & $\begin{array}{l}\text { Both } \\
\text { sexes }\end{array}$ & $M$ & $\mathrm{~F}$ & $\begin{array}{l}\text { Both } \\
\text { sexes }\end{array}$ & $\mathbf{M}$ & $\mathrm{F}$ & $\begin{array}{l}\text { Both } \\
\text { sexes }\end{array}$ \\
\hline $\begin{array}{l}\text { Hypnotics } \\
\text { Minor tranquillisers } \\
\text { Major tranquillisers } \\
\text { Antidepressants }\end{array}$ & $\begin{array}{r}831 \\
1241 \\
569 \\
623\end{array}$ & $\begin{array}{l}1639 \\
3087 \\
1311 \\
1699\end{array}$ & $\begin{array}{l}2470 \\
4328 \\
1880 \\
2322\end{array}$ & $\begin{array}{l}2 \\
3\end{array}$ & $\begin{array}{r}5 \\
13 \\
3 \\
9\end{array}$ & $\begin{array}{r}5 \\
15 \\
3 \\
12\end{array}$ & $\begin{array}{l}1 \cdot 6 \\
4.8\end{array}$ & $\begin{array}{l}3 \cdot 1 \\
4 \cdot 2 \\
2 \cdot 3 \\
5 \cdot 3\end{array}$ & $\begin{array}{l}2 \cdot 0 \\
3 \cdot 5 \\
1 \cdot 6 \\
5 \cdot 2\end{array}$ \\
\hline All psychotropics & 2727 & 5508 & 8235 & 5 & $26^{*}$ & 31 & $1 \cdot 8$ & $4 \cdot 7$ & $3 \cdot 8$ \\
\hline
\end{tabular}

* Four women took drugs from two groups.

the rates for antidepressants and minor tranquillisers was not statistic- $\vec{\Phi}$ ally significant $(\chi i=0 \cdot 7)$.

Table III shows a similar analysis of self poisoning with psycho- ڤ tropic drugs according to sex and age. Women were more likely $\vec{\circ}$

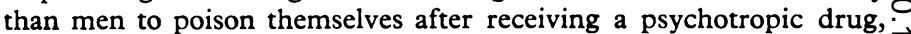
though again this difference was not significant $\left(\chi_{\hat{i}}=3.3 ; 0.05<p<\overrightarrow{\vec{J}}\right.$ $0 \cdot 10$ ). No one aged 10-14 years took an overdose of a prescribed $\stackrel{\sigma}{\omega}$ psychotropic drug. The rate was highest in patients aged 15-29 years:음 of 1945 given psychotropic drugs during the two years, 17 (8.7 per 1000) took overdoses of their drugs. The rate of self poisoning was lower among older patients, and analysis of all age groups showed a $\sigma$ highly significant decline in the rate with increasing age $\left(\chi_{1}^{\text {? }}\right.$ for trend $=\mathscr{E}$ $12.9 ; \mathrm{p}<0.001)$. The only patient over 60 years of age to take an $\mathscr{D}_{\infty}$ overdose of drugs prescribed by his general practitioner was a 63 year $\infty$ old man who died after poisoning himself with trimipramine.

TABLE III-No of patients in different age groups poisoning themselves with $\vec{N}$ prescribed psychotropic drugs in relation to total number receiving such drugs in a two year period

\begin{tabular}{|c|c|c|c|c|c|c|c|c|c|}
\hline \multirow[b]{2}{*}{ Age } & \multicolumn{3}{|c|}{$\begin{array}{l}\text { No who received } \\
\text { prescriptions }\end{array}$} & \multicolumn{3}{|c|}{ No taking overdose } & \multicolumn{3}{|c|}{ Rate/1000 recipients } \\
\hline & $M$ & $\mathrm{~F}$ & Both sexes & $\bar{M}$ & $\mathrm{~F}$ & Both sexes & $\bar{M}$ & $\mathbf{F}$ & Both sexes \\
\hline $\begin{array}{r}10-14 \\
15-29 \\
30-44 \\
45-59 \\
\geqslant 60\end{array}$ & $\begin{array}{l}109 \\
536 \\
695 \\
676 \\
711\end{array}$ & $\begin{array}{r}113 \\
1409 \\
1435 \\
1293 \\
1258\end{array}$ & $\begin{array}{r}222 \\
1945 \\
2130 \\
1969 \\
1969\end{array}$ & $\begin{array}{l}3 \\
1 \\
1\end{array}$ & $\begin{array}{r}14 \\
8 \\
4\end{array}$ & $\begin{array}{r}17 \\
8 \\
5 \\
1\end{array}$ & $\begin{array}{l}5.6 \\
1.5 \\
1.4\end{array}$ & $\begin{array}{l}9 \cdot 9 \\
5.6 \\
3 \cdot 1\end{array}$ & $\begin{array}{l}8.7 \\
3 \cdot 8 \\
2.5 \\
0.5\end{array}$ \\
\hline$\geqslant 10$ & 2727 & 5508 & 8235 & 5 & 26 & 31 & $1 \cdot 8$ & $4 \cdot 7$ & 3.8 \\
\hline
\end{tabular}

Patients who received psychotropic drugs towards the end of the two years had less chance to take an overdose during the study period. We therefore examined separately the 5600 people who were prescribed psychotropic drugs during the first year. Of these, 17 (3.0 per 1000) poisoned themselves with the drugs within 12 months of receiving them.

\section{PRESCRIBING AFTER THE EPISODE}

There were 26 episodes in which patients who had taken overdoses $N$ of prescribed psychotropic drugs were included in the study for at least $\frac{7}{O}$ a further three months. During the three months after their self poisoning, 14 patients were prescribed the same psychotropic drug and $N$ another five were prescribed a different psychotropic drug. Hence N almost three quarters of the patients received a psychotropic drug $\sigma$ from their general practitioner within three months of their admission to hospital.

\section{Discussion}

Self poisoning is a major public health problem: in one area $\stackrel{\mathbb{D}}{\stackrel{1}{\infty}}$ it accounted for $11 \%$ of all medical admissions to hospital and $\varrho$ for $30 \%$ of the emergencies. ${ }^{7}$ Although it has been shown that psychotropic drugs are the most commonly used, ${ }^{3} 7$ previous 8 studies have not been able to relate the numbers of overdoses? to the numbers of patients actually given psychotropic drugs We found that only 3 per 1000 of the patients prescribed? 
psychotropic drugs in general practice in one year used these drugs for self poisoning. This suggests that the frequency of self poisoning with psychotropic drugs owes more to the widespread prescribing of these drugs ${ }^{8}$ than to a special propensity of the patients receiving them.

Our study was confined to episodes of self poisoning that led to hospital admission or death (in or out of hospital). Nearly all such episodes should have been ascertained, since up to six discharge diagnoses were recorded for each hospital admission, and all cases of self poisoning with drugs should have been coded in the rubrics that were examined. The proportion of episodes that do not lead to hospital admission is unknown, but it may be substantial. ${ }^{9}$ Hence the overall incidence of self poisoning will be higher than the estimate obtained here.

Admissions to hospital due to self poisoning are commoner among people of lower social class. ${ }^{12}$ The general practices that we studied included patients from a fairly typical range of backgrounds, but we had no details of the socioeconomic status of the individuals in the study population. It is possible that the risk of self poisoning would be greater in a community with a higher proportion of socially deprived people.

Only about half of all the patients who took overdoses used drugs that were known to have been prescribed by their general practitioner. Some of the rest may have had the drugs prescribed before the study began, though the observation that the median period between prescribing of a drug and self poisoning was 13 days suggests that this would not have been very common. Many patients would have purchased their drugs over the counter (especially in the case of analgesics such as aspirin); some would have received them from psychiatrists or other doctors; and some would have used medicines belonging to relatives or friends. In Jones's study of self poisoning, ${ }^{7}$ at least half of the drugs obtainable only on prescription had been prescribed for another person, though others have reported a lower proportion. ${ }^{310} \mathrm{By}$ the same token, some of the drugs prescribed for our population could have been used in overdoses by other patients.

Despite the fact that our study population included 43000 people during the two years, the number of episodes was too small to allow rates of self poisoning with different groups of psychotropic drugs to be compared with confidence. Nevertheless, the higher rate (per 1000 recipients) in women than in men may well be real. There was also a highly significant decline in the rate with increasing age. The high rate in women aged 15-29 years is consistent with the predominance of this group among self poisoners admitted to hospital. ${ }^{1}$

Weissman ${ }^{1}$ highlighted a common dilemma in the prescribing of psychotropic drugs: "Patients who most often require these medications also offer the greatest risk of misusing them." This is a particular problem after a patient has taken an overdose. Although much effort has been devoted to finding means of secondary prevention of self poisoning, ${ }^{11-13}$ little is known about the drugs patients receive after an episode. We were surprised to discover that almost three quarters of patients who had taken overdoses of prescribed psychotropic drugs received further'psychotropic drugs from their general practitioner during the three months after their admission to hospital.

An unexpected observation during this study was that, among the 55 women who poisoned themselves, 11 had at least one gynaecological admission during the two years, including five who had abortions. This finding deserves further investigation in a larger sample of self poisoners.

Most self poisoning attempts are impulsive, ${ }^{14}$ so if fewer psychotropic drugs were available they might less often be abused in this way. Our finding that a relatively small proportion of the patients given psychotropic drugs take overdoses should enable doctors to prescribe with more confidence when such drugs are necessary. Nevertheless, psychotropic drugs should never be used lightly-especially in young adults, who are a high risk group for self poisoning.

We thank our general practitioner colleagues for their help. Dr $\mathrm{J}$ A Baldwin kindly provided data from the Oxford Record Linkage Study.

\section{References}

1 Weissman MM. The epidemiology of suicide attempts, 1960 to 1971. Arch Gen Psychiatry 1974 ;30:737-46.

${ }^{2}$ Kreitman N, ed. Parasuicide. London: John Wiley, 1977.

${ }^{3}$ Morgan HG, Burns-Cox CJ, Pocock H, Pottle S. Deliberate self-harm: clinical and socio-economic characteristics of 368 patients. $\mathrm{Br} \mathcal{F}$ Psychiatry 1975;127:564-74.

4 Turner RJ, Morgan HG. Patterns of health care in non-fatal deliberate self-harm. Psychol Med 1979;9:487-92.

5 Skegg DCG, Doll R. Record linkage for drug monitoring. $\mathcal{f}$ Epidemiol Community Health $1981 ; 35: 25-31$.

${ }^{6}$ Evans JG. Deliberate self-poisoning in the Oxford area. $\mathrm{Br} \mathcal{F}$ Prev Soc Med 1967;21:97-107.

${ }^{7}$ Jones DIR. Self-poisoning with drugs: the past 20 years in Sheffield. Br Med 7 1977; : $28-9$.

${ }^{8}$ Skegg DCG, Doll $R$, Perry J. Use of medicines in general practice. Br Med f 1977;i:1561-3.

${ }^{9}$ Kreitman N. Services for parasuicide and the place of a poisonings unit. In: Farmer R, Hirsch S, eds. The suicide syndrome. London: Croom Helm, 1980:259-62.

10 Holding TA, Buglass D, Duffy JC, Kreitman N. Parasuicide in Edinburgh: a seven-year review 1968-74. Br f Psychiatry 1977;130:534-43.

${ }^{11}$ Chowdhury N, Hicks RC, Kreitman N. Evaluation of an after-care service for parasuicide (attempted suicide) patients. Social Psychiatry $1973 ; 8: 67-81$.

12 Gibbons JS, Butler J, Urwin P, Gibbons JL. Evaluation of a social work service for self-poisoning patients. $\mathrm{Br} \mathcal{F}$ Psychiatry 1978;133:111-8.

${ }^{13}$ Hawton K, Bancroft J, Catalan J, Kingston B, Stedeford A, Welch N. Domiciliary and out-patient treatment of self-poisoning patients by medical and non-medical staff. Psychol Med 1981;11:169-77.

${ }^{14}$ Smith AJ. Self-poisoning with drugs: a worsening situation. $\mathrm{Br} \mathrm{Med} \mathcal{f}$ 1972 ;iv:157-9.

(Accepted 4 fanuary 1983)
WOAD hath divers large leaves, long, and somewhat broad withal, like those of the greater plantain, but larger, thicker, of a greenish colour, somewhat blue withal. From among which leaves rises up a lusty stalk, three or four feet high, with divers leaves set thereon; the higher the stalk rises, the smaller are the leaves; at the top it spreads divers branches, at the end of which appear very pretty, little yellow flowers, and after they pass away like other flowers of the field, come husks, long and somewhat flat withal; in form they resemble a tongue, in colour they are black, and they hang bobbing downwards. The seed contained within these husks (if it be a little chewed) gives an azure colour. The root is white and long. It is sowed in fields for the benefit of it, where those that sow it, cut it three times a year. It flowers in June, but is long after before the seed is ripe.

I + is a cold and dry plant of Saturn. Some people affirm the plant to be destructive to bees, and fluxes them, which, if it be, I cannot help it. I should rather think, unless bees be contrary to other creatures, it possesses them with the contrary disease, the herb being exceeding dry and binding. However, if any bees be diseased thereby, the cure is, to set urine by them, but set it in a vessel, that they cannot drown themselves, which may be remedied, if you put pieces of cork in it. The herb is so drying and binding, that it is not fit to be given inwardly. An ointment made thereof stanches bleeding. A plaister made thereof, and applied to the region of the spleen which lies on the left side, takes away the hardness and pains thereof. The ointment is excellently good in such ulcers as abound with moisture, and takes away the corroding and fretting humours: It cools inflammations, quenches St Anthony's fire, and stays defluxion of the blood to any part of the body. (Nicholas Culpeper (1616-54) The Complete Herbal, 1850.) 